\title{
Analysis of Society Perspective about Vintage Fashion Using Deconstruction Approach
}

Assayyidah Bil Ichromatil IImi

${ }^{1}$ Department of English Literature, Faculty of Humanities, Universitas Islam Negeri Maulana Malik Ibrahim Malang

\begin{abstract}
Nowadays, society's perspective about vintage fashion as old-fashioned can be changed. This study aims to discuss the alteration perspective of society about vintage style. This discussion was conducted to see the other side of vintage fashion. This research is different from other fashion studies because it wants to show how to view the value of a fashion, not generally, especially using the deconstruction approach. This study used qualitative methods in the form of interviews to get the data. The interviewees of this research were four young women who like to follow fashion development through social media that can be seen in their posts and the influencer they follow. Their opinions are used as society representatives about vintage fashion. It will be connected with the theory of deconstruction like 'Difference.' In this case, people's perspective on vintage fashion changes due to the influence of influencers from various social media so that vintage fashion can be juxtaposed with modern style today. Therefore, vintage can get an identity as nowadays's clothes.
\end{abstract}

\section{Keywords}

deconstruction, development, perspective, philosophy, society, vintage fashion 


\title{
Analysis of Society Perspective about Vintage Fashion Using Deconstruction Approach
}

\author{
Assayyidah Bil Ichromatil IImi
}

\section{INTRODUCTION}

Fashion has been one of the most popular things which are being discussed among people in the world. The Matters related to popular style or practice, especially in clothing, footwear, lifestyle products, and others, become society's interest in their appearance. People are constantly competing to follow the development of fashion trends, either the latest version of trends fashion or modern and ancient fashion, that has reappeared as a trend now. The development of fashion, which is always followed by all people globally, shows that fashion is a prevalent thing for society.

This paper will focus on one of the old fashion styles, the most well-known old fashion globally, called Vintage fashion. In its development, vintage is more familiar when associated with the world of fashion. Some examples of vintage fashion clothes such as circle skirts, crop tops, pussy-bow blouses, bishop sleeves, floral skirts, Shoulder Pads show that vintage fashion has various styles and very popular in its time. Vintage fashion became a notable trend of society between the 1920s until 1960s. At that time, the vintage style was favored by people in terms of choosing clothes and accessories. The connotation of vintage fashion is always associated with something ancient and antique because it appeared in the previous era.

Fischer argues that vintage fashion turns into an abstract category that portrays old clothes in general, and no longer refers to buying new clothes that portray old clothes in general, and no longer refers to buying new clothes as an investment in the future [1]. Meanwhile, in this millennium era, vintage fashion has resurfaced as a fashion trend anymore. Now, A statement that said that vintage is always identical to the old times received a rejection from society, especially among young people. The emergence of vintage in this era caused some changes in people's perspective on the stigma of antiquity that became the identity of vintage fashion.

The image of Vintage Fashion in this century is lustrous anymore. The antiquity inherent in the model of vintage is considered invalid by society because vintage fashion continues to emerge with its distinctive style and increasingly attracts many consumers to use it as current fashion trends [1-3]. According to Aleit Veenstra and Giselinde Kuipers, one of the causes of vintage has attracted many people because there is a philosophy in the value of vintage itself. Therefore, vintage fashion is still very commercially appropriate regardless of the age of the vintage style [3].

This article aims to analyze the perspective of society on vintage fashion, especially in the deconstruction approach. Changes in views of vintage fashion have proven that vintage fashion deconstructs people's thinking that connects vintage values with antiquity. Also, the purpose of this article is to find out how society views the popularity of vintage fashion today and the reasons why people change their opinions on the value of vintage fashion. The responses given by the interviewees will be related to how their opinion of the vintage's identity is associated with antiquity. The results of the answers will be explained in the part discussion.

\section{Vintage Fashion}

Vintage is one of the fashion terms commonly used to refer to all old clothing styles. The philosophy of Vintage itself is old and high quality. The term of Vintage was known from the 1920s. However, the 1920s vintage version was for old items that have high quality and are not always related to fashion but for classic goods such as furniture, musical instruments, vehicles, etc. However, nowadays, Vintage is more attached to fashion, which is considered trendy. Many of the people back to wearing the style of vintage dress at this time, even though Vintage is identical with antiquity. Unconsciously, Vintage has adopted the concept of deconstruction that vintage identity is not always related to antiquity, in contrast to artsy, hipster, grunge, and others that are considered more modern because it appeared in the 21st century. Vintage is no less elegant than some of the modern fashion that has mentioned earlier. Vintage has defeated modern fashion because it has more consumers even though the ancient identity remains attached to the Vintage [2]. 

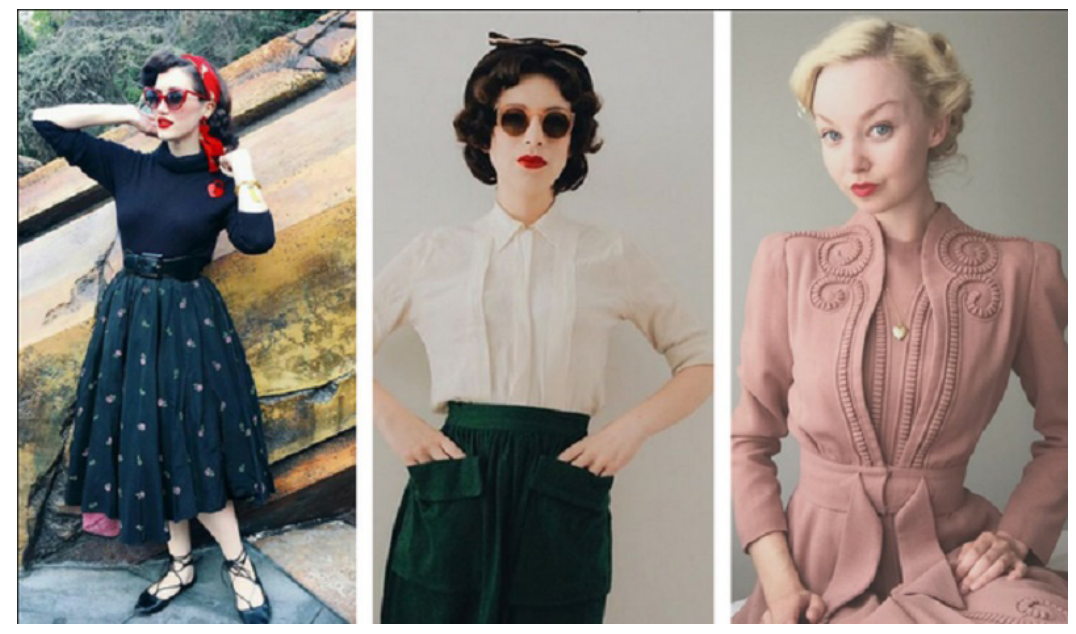

Figure 1. Vintage Style (Photo: Vintageindustry)

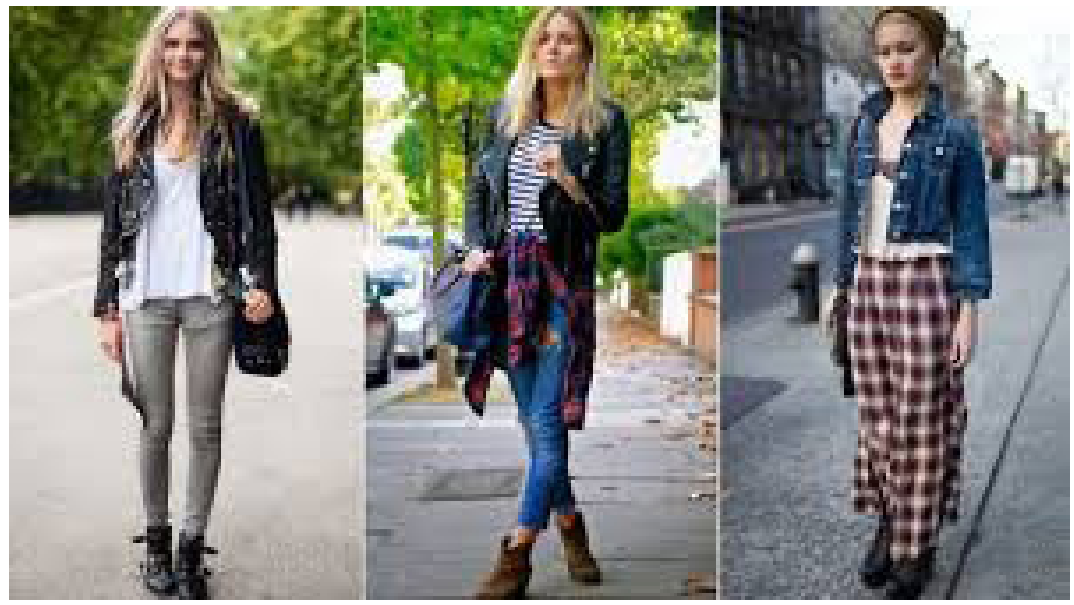

Figure 2. Grunge Style as Modern Fashion (Photo: Fashionlady.in)

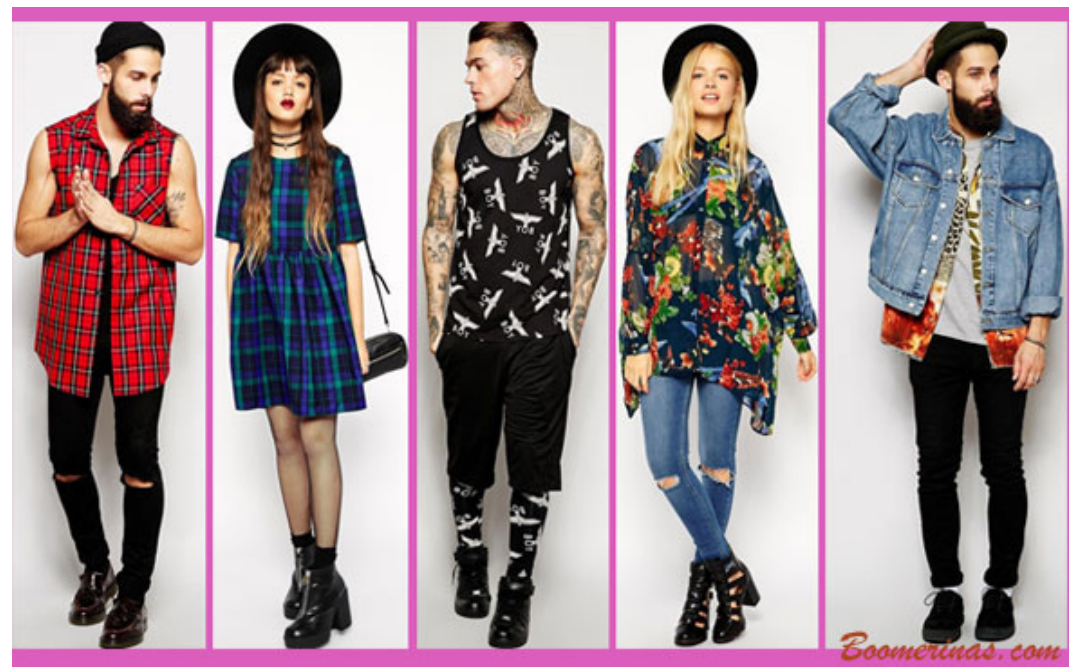

Figure 3. Hipster Style as Modern Fashion

(Photo: Boomerina.com)

Depends on the pictures above, we can see the visual difference between vintage and modern fashion. Vintage has the characteristics of its color, pattern, and model. Vintage is identical with pastel color, practical and straightforward style, and it also uses polka dots and tiny floral motifs for its pattern. Vintage also uses ribbon and zipper, which began to be introduced in the vintage era. Meanwhile, different from vintage style, modern style has its characteristics. Some modern styles adapted from vintage style, although they made their characteristics. For example, grunge style is one of modern style. This style emerged during the rise of grunge music. Grunge fashion has the characteristics such 
as jeans, t-shirt, and plaid shirts. These kinds of punk style, but it is not a radical punk style. Another modern style is hipster style. Hipster style appears from the idea of homeless in the United States. This style emphasizes DIY. The characteristics of this fashion are diverse such as skinny jeans, boots, hats, oversized clothes, etc. Therefore, from the explanation, we can conclude if vintage as old-fashioned has so much different from the variety of modern style.

\section{Deconstruction}

Deconstruction is the theory triggered by Jacques Derrida, which refers to the rejection of the theory of structuralism. Jacques Derrida is known as the French philosopher of Western philosophy for analyzing the nature of language, writing, and meaning, which are very controversial but very influential in many intellectual worlds at the end of the 20th century (Source: Internet). Deconstruction attempts to give meaning or philosophy that is different from the structural significance of heterogonous variety [4]. According to Derrida, we can claim that deconstruction provides a particular manner and unifying principle. So, Derrida conveyed the concept in giving philosophy to the cases strictly related to a structural concept by deconstruction [4].

An example of the theory that Jacques Derrida has deconstructed was Difference and Binary Opposition. One of the structuralism linguists, Ferdinand de Saussure, was the person who established the term 'Difference.' The concept of 'Difference' is related to the paradigm produced by Saussure; namely, sign, signified, and signifier. 'Difference' explains that a language is a structural form that shows signs are being organized [5]. The term 'Difference' has spatial properties, in which meaning is made in the relations between signs that are locked together in a mechanical structure [6]. It means, according to Saussure, it can be analogized like one word can only have one concept and one meaning. This gets criticism from Derrida. According to Derrida, language is not only structural but also temporal. Derrida deconstructed 'Differences' with established 'Difference,' which tells that meaning depends on structural differences, but it has temporal relations [6]. 'Difference shows that a signifier can produce more than one signified. It means one word can have more than one meaning or concept. It depends on the situation and the time. Because the truth is not just only one, it was absolute and universal.

Another theory that deconstructed by Derrida is Binary Opposition by Levi' Strauss. According to Derrida, Binary Opposition, which is important for structuralism, is never a simple structural [6]. There is a hidden meaning behind the theory of binary opposition. Derrida said that there is always power behind the application of binary opposition [6]. 'Power' shows the term of dominant position about the other. Therefore, the dominant will always get the privilege of its position. In this case, Derrida proves that something related to binary opposition is always related to power. Therefore, deconstruction theory can make the meaning of words and claims change from what is understood in general through critical thinking in giving a sense.

According to the explanation above, structuralism and deconstruction have a different perspective to see vintage fashion. Structuralism gives vintage as "old-fashioned" as the sign. However, in deconstruction, it can be criticized why vintage is old-fashioned whereas it is still good to use in this era.

\section{RESEARCH METHOD}

Based on the research question, this study is using the qualitative method. The interviewees of this research were four young women who like to follow fashion development through social media, and proven by their following on their Instagram and their daily outfits for their Instagram posts. The study's data source was the result of interviewing four young women about what has been written in the research question in the form of recording through the WhatsApp application. The four people interviewees represented people's views about the return of vintage fashion in this era. The researcher deliberately did not take the informants from fashion qualifications and only used ordinary people as informants because the researcher wanted to know the public's general view regarding vintage fashion. The data were provided in the form of dialogue by transcribing the recording of the interview. After collecting the interviews and transcribing the interview result, the researcher interpreted the answers that the interviewees gave. After that, the resulting interpretation will be associated with the theory of deconstruction.

\section{RESULT \& DISCUSSIONS}

This article wants to discuss how society changes its perspective about vintage fashion, which has an identity ad old-fashioned. The researcher sees the phenomena of shifting perspective by applying it to the deconstruction approach. Vintage fashion in the present time has changed society's perspective about its ancient. The researcher wants to show if society has to see the phenomena or others differently because everything in this world has its philosophy. All of the identities related to phenomena, words, things or more, always have their power [6]. Thus, Derrida said if all interpretations of phenomena never are stable [4]. 
All of the researcher's opinion above is supported by the answers from the interviewees. The researcher interviewed young women, namely, I (21 years old) as a first informant, D (20 years old) as a second informant, B ( 21 years old) as the third informant, and the last $\mathrm{H}$ ( 21 years old) as the fourth informant. These four interviewees will represent the society regarding how vintage fashion can deconstruct its identity as old-fashioned.

In the first question, they were asked about their opinions while vintage fashion reappears in this modern era. The first, third, and fourth informant said that the emergence of vintage fashion is considered a natural thing in the current era and is often found. The first informant explained that most society likes something interesting that vintage values can represent. That statement proves if vintage fashion shows authentic identities (alleeit). Meanwhile, the report from the second informant about the productive age of fashion consumers between 16-40 is one of the causes of vintage fashion growing because people's lifestyles become consumptive and try to follow the existing trends. Besides that, everyone knows if there are many famous brand release vintage modes in this 21 st era that make vintage raised again [7].

Most of them explained that the emergence of vintage fashion in this era was a common thing from these interviews. They assumed that vintage fashion that is considered old-fashioned has reappeared because people choose a different fashion from other societies. The nature of someone who wants to look different from the others is one reason for the return of this vintage fashion. Cassidy said that vintage consumers and vintage retailers show the movement of vintage fashion's viewpoints [8]. It is related with how the first, third, and fourth informant opinion. The statement had given by the interviewees is contrary to the theory of binary Opposition. Maybe at first, the appearance of vintage fashion in the modern era seemed strange. However, the identity of vintage fashion can change when viewed through deconstruction theory because it concerns dealing with the fact that opposites interact and meaning becomes unstable [5].

Another question has been given to find out why people's views of vintage fashion today are different from the past, for example, in the last ten years. In this question, the researcher got a different perspective from the interviewees. The first informant said that influencer, or we usually called it selebgram or else, is the most influential part of raising vintage fashion and changing the social perspective. This is one of the correct opinions because fashion designers include vintage as their inspiration, which is caused by the growth of technology, like the power from an influencer in social media [8]. This statement relates with the answer from the third informant who said, "Maybe at this time, fashion is carried by well-known brands like perhaps brands from abroad, it brought with technological sophistication." The answer of the third informant supports the answer which the first informant gives. The point is that the role of influencer and technology has pulled up vintage fascination.

Other than that, the fourth informant said, "In my opinion, if in the present time even though people still wear vintage, it is still in the merger with the present situation. So, the vintage is not like in the past, but there is still a present nuance, and it will mix like that.". The statement which the fourth informant gives shows the form of deconstruction theory of vintage fashion. one way to deconstruct a vintage fashion image by giving a new nuance and collaborating vintage with current fashion because the form of deconstruction can give new identity and also the philosophy which makes vintage not be glued in one meaning [4].

From those interviews, the researcher interprets why they had different perspectives about vintage fashion between the present and past. Most of them answered that if technology is the most influential thing behind the return of vintage fashion. One of them said it is because some influencers behind the technology give the references of fashion to society. The influence that influencers and social media have given has deconstructed the ancient value of vintage fashion. It is related to the concept of deconstruction theory about 'Difference, which said if one word can have more than one concept depends on the time and context [6]. In this case, time is the main highlight of why people's perspectives change towards vintage fashion. Time became the main highlight because people deconstructed vintage fashion by mixing it with a modern vibe.

The last question was about their opinion when vintage fashion has always been linked to oldfashioned. Almost all of them give the answers related to how they deconstruct the identity of vintage fashion. The first, third, and fourth informants said they disagree when vintage fashion has always been linked to old-fashioned. Meanwhile, the second informant said that vintage fashion is proper to call old-fashioned because it has the history behind vintage itself. Although there is a different opinion between them, all of them said that vintage fashion is still worth using today. 
Tabel 1. The data from the interviewees about vintage.

\begin{tabular}{|l|l|l|l|}
\hline Informants & Vintage reappears & Reason of the different era & Vintage as Old-fashioned \\
\hline 1 & Understandable & Influencer & Disagree \\
2 & Understandable & Brands & Agree \\
3 & Understandable & Influencer & Disagree \\
4 & Understandable & Time and situation & Disagree \\
\hline
\end{tabular}

Based on the answers that have been given, this is related to deconstruction theory, which criticized 'Binary Opposition.' Binary Opposition explained hidden things behind the word's meaning or usually called a power [6]. The researcher interprets it as criticized as 'binary opposition' because it will compare with modern fashion like artsy, hipster, grunge, and others, which has power as modern fashion due to their launch time. Vintage appears earlier than other modern fashion, so that vintage is valued as old-fashioned. Thus, with the deconstruction theory, this case tends to describe a situation or condition in which all identities and meanings can occur so that it can be repeated in an unlimited number of potential addresses but not determined as described in the term 'Differance' [5].

From all of the answers above, the researcher almost has the same perspective as the interviewees. We have to remember if deconstruction in the form of structuralism criticism. In structuralism, there is a thing called a sign. Deconstruction criticizes the meaning behind the sign, which is proposed by the term structuralism. In the case of vintage fashion, the designation as "oldfashioned" happened because the meaning behind "old-fashioned" came from the old era (19201960). That is one of the analyses using one of the deconstruction concepts like "differance." In this case, deconstruction shows that it found the binary opposition concept between both vintage and modern. Binary opposition shows that there is a power behind two sign that has the opposite meaning. Derrida said that power gives an advantage to one of them. In fashion, modern fashion has more power because it is considered the fashion worthy of use in this era; in other words, vintage is considered too old-fashioned to use in this era. Because besides the reason is about the era of emerged vintage, vintage also has a simple style rather than another modern fashion such as color, accessories, pattern, etc. Modern fashion shows the variety of fashion development which also has more various styles than vintage.

Based on society's answer, we also know that actually, they did not realize If the society also applied the theory of deconstruction in this era. Their opinion about vintage is not worthy to say as oldfashioned; they also found a common goal of deconstruction. The researcher agrees with one of the interviewee's answers about combine vintage with nowadays clothing. We can combine vintage color and pattern by wearing jacket jeans and wearing boots from hipster fashion to create more variety and stylish. We also can apply another style like grunge, emo, or else to make it more modern but does not make the value of vintage lose by modifying the taste of fashion through creative design activities.

\section{CONCLUSION}

The phenomenon of the return of vintage fashion in this era has become a common thing to be a fashion trend by the public. People no longer see vintage clothing as an old-fashioned style. The antiquity identity of vintage fashion is judged only because when vintage fashion appears. If juxtaposed with the emerging trend, vintage fashion is still very feasible and appropriate for the current era. The alteration in perspective on vintage fashion identity is caused by technology such as social media, which is brought by influencers. The role of influencers can apply the deconstruction theory to changes in people's views about vintage fashion. Besides, the combination of fashion between vintage and modern style can also lift vintage shades into outdated clothing. Therefore, for deconstruction theory, vintage clothing is no longer old-fashioned and can be used as modern clothing.

This study also invites readers to interpret an event or phenomenon critically without seeing the value or identity attached to the phenomenon. In addition, the researcher hopes that there will be some research that can interpret things using the theory of deconstruction not only about a literary work but also can be applied to the phenomenon that happens around us.

\section{ACKNOWLEDGEMENT}

First of all, I thank Allah because I cannot finish my article well without Allah's relief. I thank my parents and also all my friends who supported me in completing this article. Besides that, I also thank Mr. Miftahul Huda as my lecturer in Cultural studies courses, who has helped me improve this article. 


\section{REFERENCES}

[1]. Fischer, N.L. Vintage, the First 40 Years: The Emergence and Persistence of Vintage Style in the United States. Culture Unbound, 2015; 7: 45-66.

[2]. Cervellon, M. Carey, L. \& Harms, T. Something old, something used. International Journal of Retail \& Distribution Management, 2012; 40: 956-974.

[3]. Veenstra, A. \& Kuipers, G. It Is Not Old-Fashioned, It Is Vintage, Vintage Fashion and The Complexities of 21st Century Consumption Practices. Sociology Compass, 2013; 7: 355-365.

[4]. Sallis, J. (ed) Deconstruction and philosophy: The texts of Jacques Derrida. University of Chicago Press, 1987.

[5]. Garg, N. Kumar, S. \& Sharma, V. Concepts of Difference and Differance A Comparative Study of Saussure and Derrida. Language in India, 2014; 14: 141-147.

[6]. Storey, J. (ed) Cultural theory and popular culture: A reader. Pearson Education,; 1.

[7]. Özbek, T. Why Vintage Style? Investigation of Vintage Clothing Motivations of Consumers. European Journal of Multidisciplinary Studies, 2018; 7: 173.

[8]. Cassidy, T.D. \& Bennett, H.R. The Rise of Vintage Fashion and the Vintage Consumer. Fashion Practice, 2012; 4: 239-261. 